\title{
Weihnachtsgratifikation und Urlaub nach Freistellung in der Kündigungsfrist?
}

\author{
Das Landesarbeitsgericht (LAG) Mainz hat sich in seinem Urteil vom 20.10.2016 (7 Sa 171/16) mit \\ der Frage befasst, inwieweit ein Zahnarzt bei einer Praxisschließung Ansprüche seiner Mitarbei- \\ ter bei einer Freistellung verrechnen kann.
}

\section{Der Fall}

Im konkreten Fall kündigte ein Zahnarzt am 29.04.2015 ein Arbeitsverhältnis aus betriebsbedingten Gründen: Es handelte sich um die Schließung der Zahnarztpraxis zum 30.11.2015. Die Praxis war bereits ab Mai 2015 geschlossen.

Die gekündigte Arbeitnehmerin forderte im Juli 2015 unter anderem die zweite Hälfte des Weihnachtsgeldes für die Jahre 2013 und 2014, woraufhin der Zahnarzt die Arbeitnehmerin anwaltlich freistellen ließ. Im Wortlaut hieß es: „unwiderruflich unter Anrechnung sämtlicher etwaiger bestehender Urlaubsund Freizeitausgleichsansprüche bis zum Ablauf der Kündigungsfrist zum 30.11.2015, die Freistellung Ihrer Mandantin von der Arbeitsleistung“.

Hierauf klagte die Arbeitnehmerin und machte unter anderem Ansprüche auf Weihnachtsgeld für die Jahre 2013 und 2014 nebst Zinsen geltend.

\section{Die Entscheidung}

Mit seiner Berufung gegen ein ablehnendes Urteil des Arbeitsgerichtes Trier hatte der Zahnarzt keinen Erfolg. Nach Auffassung des LAG Mainz hatte die Arbeitnehmerin Anspruch auf die Zahlung weiteren Weihnachtsgeldes für die Jahre 2013 und 2014 in Höhe von jeweils 930,00 Euro brutto.

Nach Auffassung des LAG Mainz enthielt der konkrete Arbeitsvertrag eine Zusage der Zahlung einer Weihnachtsgratifikation in Höhe eines vollen Monatsgehalts. Das ergebe sich bereits aus dem Wortlaut der vertraglichen Regelung „wird gezahlt". Eine Formulierung, nach der vom Arbeitgeber ein Bonus oder eine Gratifikation gezahlt wird oder der Arbeitnehmer ei- nen Bonus oder eine Gratifikation erhält, sei typisch für die Begründung eines Entgeltanspruchs. Dem stünde auch nicht entgegen, dass die jährliche Weihnachtsgratifikation „bis auf weiteres" gezahlt werden soll. Auch diese Formulierung lasse sich nur dahingehend verstehen, dass der Arbeitnehmerin eine Weihnachtsgratifikation zustehe.

Etwas anderes ergebe sich auch nicht aus dem im Arbeitsvertrag enthaltenen Freiwilligkeitsvorbehalt, wonach die Zahlung einer Weihnachtsgratifikation - auch nach wiederholter Zahlung - keinen Rechtsanspruch begründen soll und „freiwillig gezahlt“ wird. Diese Regelung verstoße gegen das Transparenzgebot des $\S 307$ Abs. 1 S. 2 BGB und sei deshalb unwirksam. Nach $₫ 307$ Abs. 1 S. 2 BGB könne sich eine unangemessene Benachteiligung auch daraus ergeben, dass die Bestimmung nicht klar und verständlich sei. Der Zahnarzt habe auch nicht substantiiert zu einem Verzicht der Arbeitnehmerin auf die weitere Weihnachtsgratifikation für die Jahre 2013 und 2014 vorgetragen.

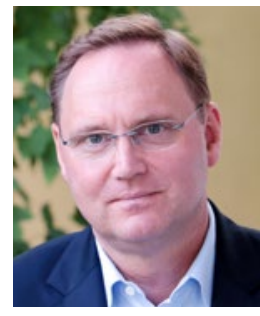

RA Michael Lennartz

www.lennmed.de

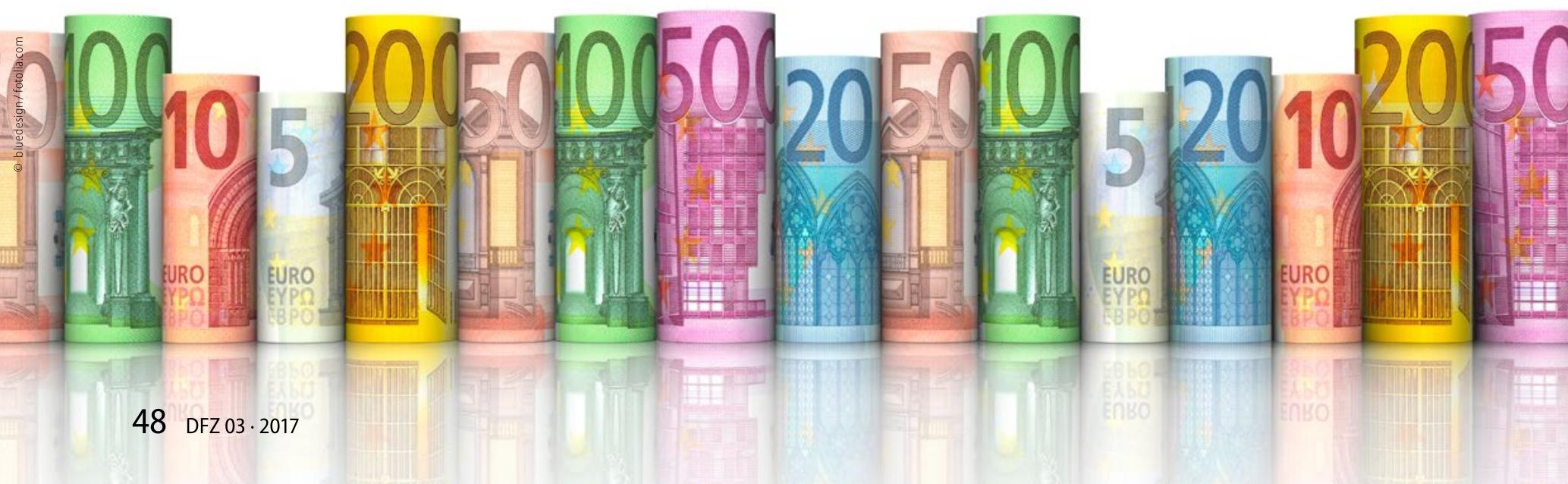

